\title{
Growing Older Out of the Closet: A \\ Descriptive Study \\ of Older LGB \\ Persons Living in \\ Lisbon, Portugal
}

The International Journal of Aging and Human Development 2019, Vol. 88(4) 422-439

(C) The Author(s) 2019

Article reuse guidelines: sagepub.com/journals-permissions DOI: $10.1177 / 0091415019836107$ journals.sagepub.com/home/ahd

(S)AGE

\author{
Henrique Pereira' (D, \\ Brian de Vries ${ }^{2}$ (D, \\ António Serzedelo ${ }^{3}$, \\ Juan Pedro Serrano ${ }^{4}$, \\ Rosa Marina Afonso', \\ Graça Esgalhado', and \\ Samuel Monteiro'
}

\begin{abstract}
There is a paucity of information regarding the needs of older Lesbian, Gay, and Bisexual (LGB) adults in Portugal; to help address this imbalance, this article describes a sample of Portuguese LGB older adults living in the large, urban center of Lisbon. Specifically, the article describes (a) the broad sociodemographic characteristics of LGB 60 years of age or older; (b) the type and level of social support and the nature of interpersonal relationships of these older LGB persons; (c) their physical and sexual health; and (d) the experiences and concerns when accessing social and health-care services, including disclosing their identity to social and health professionals. Across these areas, we further seek to evaluate
\end{abstract}

\footnotetext{
'University of Beira Interior, Covilhã, Portugal

${ }^{2}$ San Francisco State University, CA, USA

${ }^{3}$ Opus Gay Association, Lisbon, Portugal

${ }^{4}$ University of Castilla-La Mancha, Albacete, Spain
}

\section{Corresponding Author:}

Henrique Pereira, University of Beira Interior, R. Marquês de Ávila e Bolama, 620I-00I, Covilhã, Portugal. Email: hpereira@ubi.pt 
any differences attributable to gender and compare our results to those in the literature, largely derived from North American studies.

\section{Keywords}

aging, Lesbian, Gay, and Bisexual older adults, demographics, Lisbon, Portugal

\section{Introduction}

Despite the scientific and social-political advances made in Portugal related to Lesbian, Gay, Bisexual, and Transgender (LGBT) persons, including the introduction of a nondiscrimination clause on the basis of sexual orientation in the Portuguese Constitution in 2004, the 2010 law allowing same-sex couples to marry, and the 2016 law allowing same-sex couples to adopt and joint-adopt children (Pereira \& Monteiro, 2016), discriminatory practices continue to exist (Lopes, Oliveira, Nogueira, \& Grave, 2017). That is, even as the Portuguese Constitution now provides protection against (individual) discrimination and the State is officially neutral, society is still culturally influenced by Catholic traditions (Oliveira, Costa, \& Nogueira, 2013) effectively rendering the law a site of (relational) discrimination. For example, according to the European Union LGBT Survey (European Union Agency for Fundamental Rights, 2014), 51\% of Portuguese respondents felt discriminated against or harassed on the grounds of sexual orientation in the last 12 months.

Although the study of the ageing process is currently an important and wellexplored field of scientific knowledge, much still remains to be learned about LGBT aging (Brennan-Ing, Seidel, Larson, \& Karpiak, 2014). This is particularly the case in Portugal, where only two papers in the published literature were found in the field of aging perceptions (Pereira et al., 2017), and family integrity (Marques \& Sousa, 2016) of LGBT persons. The aging experiences of transgender persons are even more complex - integrating gender identity and sexual orientation with the potentially exacerbating effects of age. For clarity of purpose, the focus of this study will be on cisgender LGB older adults.

From the general and primarily North American literature, several findings suggest increased risk of isolation and lack of support in LGB older adults (Fredriksen-Goldsen et al., 2013). For example, older LGB persons often have specific concerns about traditional medical care due to their sexual orientation (Sharek, McCann, Sheerin, Glacken, \& Higgins, 2015). At the same time, LGBT persons also may have different (and perhaps greater) health-care needs when compared with general population. Wallace, Cochran, Durazo, and Ford (2011) note that LGB individuals reported poorer health than general population. Fredriksen-Goldsen et al. (2012) found that $47 \%$ of the older LGB adults 
participating in their study had at least one disability; one third met the clinical threshold for depression.

Health issues and concerns, including the interaction with health-care professionals, are central to the experience of aging among most older adults, and perhaps especially LGB older adults. LGB older adults do not always reveal themselves (i.e., "come out") to their health practitioners (MetLife Mature Market Institute, 2010) . Guardedness in such intimate and personal encounters has potentially far-reaching implications including keeping hidden sexuality concerns and problems. The anticipated fear of discrimination is associated with delayed or diminished seeking of health-care services by older LGB people (Jackson, Johnson, \& Roberts, 2008), thus compromising the type and quality of health care provided. Even less is known about the sexual well-being, other than HIV-status, of older LGB persons - part of an overall inattention to sexuality in general among older adults.

At the same time, LGB older adults lack the typical informal social resources of heterosexual older adults (de Vries \& Hoctel, 2007). Consequently, many LGB adults will need formal support as they grow older as delivered by traditional health and social service agencies who, in general, operate under more heteronormative assumptions and often do not recognize LGB identities and partnerships (Hughes, 2007).

Studying the experiences of older LGB persons is thus important given that LGB older adults face important challenges as they age, namely, high levels of mental and physical morbidity, the lack of social support networks and persistent barriers. Since there is a lack of information regarding the needs of older LGB adults in Portugal, the aim of this article is to describe a group of Portuguese LGB older adults living in the largest city of Portugal. Our hope in this effort is to draw attention to the type and possible specific needs of LGB older adults.

After decades under Salazar's homophobic dictatorship and despite the power of the Catholic Church in Portugal, Lisbon, the capital of the country, with a little over 547,000 residents, now enjoys a gay friendly ambience, protective of LGB rights such as the 2010 law allowing same-sex couples to marry, or the 2016 law allowing same-sex couples to adopt and joint-adopt children. Data from the latest Census (Instituto Nacional de Estatística, 2012) reported that $19 \%$ of the Lisbon population was aged 65 years and over, with an increase of almost $20 \%$ since the last decade; still, there is only limited visibility for LGB older people in Lisbon. Given the fact that Portugal has one of the highest rates of an older population among European countries and very little is known about older LGB population in Lisbon, this study is of paramount importance.

The goals of this article, which is part of a larger study, named Growing older out of the closet, were fourfold: (a) to broadly describe the sociodemographic characteristics of LGB older than 60 years living in Lisbon (Portugal); (b) to describe the type and level of social support and the nature of interpersonal 
relationships of these older LGB persons; (c) to characterize their physical and sexual health; and (d) to examine the experiences and concerns when accessing social and health-care services, including disclosing their identity to social and health professionals. Across these areas, we further seek to evaluate any differences attributable to gender.

\section{Method}

\section{Participants}

A total of 101 older LGB people participated in this research. Participants were generally older than 65 years (mean age $=66.37 ; S D=5.93$; median age $=65$ ), ranging from 60 to 89 years of age. Just fewer than $60 \%$ identified as men and $40.6 \%$ of the participants identified as women. Over half, $50.5 \%$ of participants, identified as gay; $25.7 \%$ as lesbian; $12.9 \%$ as bisexual-numbers, when further distinguished by gender, unfortunately were too small to constitute groups for statistical analyses. The most common relationship status option was legally married or living in civil union (39.6\%); almost as many were single (38.6\%). Education levels were generally high ( $43.6 \%$ had completed a university degree). See Table 1 for more information on demographic characteristics of the sample.

\section{Measures}

As noted earlier, demographic data collected included age, gender, education level, marital status, number of children, and sexual orientation. Other areas of inquiry and measures included housing, income and socioeconomic resources (type of housing, with whom participant was living, retirement status, monthly income, and sufficiency of income), social support and interpersonal relations (coming out, family acceptance, support given, family of choice [referring to a person or group of people seen as significant in his or her life, including spouses, domestic partners, friends, or coworkers], emergency contact, presence of a potential caregiver, social support personnel and location, and loneliness), sexual or intimate interactions (sex with only one partner, open relationship, casual sex, no activity due to lack of partner, no activity due to health problems), HIV and STD knowledge, and, finally, access to and appraisals of social and health services (general health, coming out to health professionals, type and importance of services used, knowledge and experience of discrimination, and opinion about services and/or activities exclusively targeted at LGB older people). The survey consisted of 35 multiple response items and participants were instructed to respond to the items according to the options given. To assess survey validity, a pretest with six older LGB participants was conducted; all items were understood and minor limitations (such as grammar or layout of topics) were addressed. 
Table I. Sociodemographic Characteristics $(\mathrm{N}=10 \mathrm{I})$.

\begin{tabular}{|c|c|c|c|c|c|}
\hline Sociodemographic Characteristics & $\begin{array}{c}\text { Women } \\
(n=4 I, 40.6 \%) \\
n(\%)\end{array}$ & $\begin{array}{c}\text { Men } \\
(n=60,59 . \\
n(\%)\end{array}$ & $\begin{array}{c}\text { Total } \\
(N=10 \mathrm{I}), \\
n(\%)\end{array}$ & $\chi^{2}(\mathrm{df})$ & $p$ \\
\hline \multicolumn{6}{|l|}{ Sexual orientation } \\
\hline Gay & 0 & $5 \mathrm{I}(50.5)$ & $5 \mathrm{I}(50.5)$ & $89.517(4)$ & $.000 * *$ \\
\hline Lesbian & $26(25.7)$ & $0(0)$ & $26(25.7)$ & & \\
\hline Bisexual & $4(4)$ & $9(8.9)$ & $13(12.9)$ & & \\
\hline Other ${ }^{(I)}$ & $8(7.9)$ & $3(3)$ & II (10.9) & & \\
\hline \multicolumn{6}{|l|}{ Education } \\
\hline Up to 9 years of school & $14(13.9)$ & $12(11.9)$ & $26(26.8)$ & $13.749(4)$ & $.008 *$ \\
\hline $\begin{array}{l}\text { Secondary education } \\
\text { completed }\end{array}$ & $18(17.8)$ & $13(12.9)$ & $31(30.7)$ & & \\
\hline University degree & $9(8.9)$ & $35(34.7)$ & $44(43.6)$ & & \\
\hline \multicolumn{6}{|l|}{ Marital status } \\
\hline Single & $13(12.9)$ & $26(25.7)$ & $39(38.6)$ & I4.057 (3) & $.003 *$ \\
\hline $\begin{array}{l}\text { Married or De facto } \\
\text { Union }\end{array}$ & $18(17.8)$ & $22(21.8)$ & $40(39.6)$ & & \\
\hline Widower & $7(6.9)$ & $0(0)$ & $7(6.9)$ & & \\
\hline Divorced & $3(3)$ & $12(11.9)$ & $15(14.9)$ & & \\
\hline \multicolumn{6}{|l|}{ Retired } \\
\hline Yes & $32(3 \mid .7)$ & $42(4 I .6)$ & $74(73.3)$ & $.806(I)$ & .493 \\
\hline No & $9(8.9)$ & $18(17.8)$ & $27(26.7)$ & & \\
\hline \multicolumn{6}{|l|}{ Monthly income (in €) } \\
\hline Less than 250 & I (I.0) & $2(2.0)$ & $3(3.0)$ & $19.270(6)$ & $.004 *$ \\
\hline $251-500$ & $8(7.9)$ & $4(4.0)$ & $12(11.9)$ & & \\
\hline $501-750$ & $20(19.8)$ & $12(11.9)$ & $32(31.7)$ & & \\
\hline $751-1000$ & $3(3.0)$ & $15(14.9)$ & $18(17.8)$ & & \\
\hline $100|-| 500$ & $2(2.0)$ & $13(12.9)$ & $15(14.9)$ & & \\
\hline$|50|-2000$ & $5(5.0)$ & $9(8.9)$ & 14 (13.9) & & \\
\hline More than 2001 & $2(2.0)$ & $5(5.0)$ & $7(6.9)$ & & \\
\hline \multicolumn{6}{|l|}{ Assessment of monthly income } \\
\hline Insufficient & II (I0.9) & $13(12.9)$ & $24(23.8)$ & $.586(2)$ & .746 \\
\hline Sufficient but limited & $17(16.8)$ & $24(23.8)$ & 41 (40.6) & & \\
\hline More than enough & $13(12.9)$ & $23(22.8)$ & $36(35.6)$ & & \\
\hline \multicolumn{6}{|l|}{ Place of residence } \\
\hline Owned or rented house & $32(3 \mid .7)$ & $55(54.5)$ & $87(86.1)$ & II.583 (4) & $.021^{*}$ \\
\hline Family's house & $4(4.0)$ & $2(2.0)$ & $6(5.9)$ & & \\
\hline Friend's house & I (I.0) & - & I (I.0) & & \\
\hline Retirement home & $4(4.0)$ & - & $4(4.0)$ & & \\
\hline Other & - & $3(3.0)$ & $3(3.0)$ & & \\
\hline
\end{tabular}

Note. $M_{\text {age }}=66.37 ; S D=5.93$. Other $(I)$ refers to participants who have same-sex relations but do not identify with identity labels such as gay, lesbian or bisexual.

$* p<.05$. **p $<.001$. 


\section{Procedures}

The research was part an outreach program called "Envelhecer fora do armário" ("Growing older out of the closet") conducted by Opus Gay Association (a nongovernmental organization committed to expanding LGB inclusion in Portugal) and the Lisbon Municipality office which expressed their institutional support to the program. Inclusion criteria included being 60 years or older, self-identifying as LGB, and living in Lisbon.

Information about the study was disseminated through Portuguese LGB associations and community centers (such as Opus Gay Association) as well as through mailing lists and social networks (e.g., members of nongovernmental agencies and organizations that work with LGB people, Internet forums, and Facebook). Participants responded to this outreach online by way of a website created for this purpose. Following the study description and the clarification of the objectives of the research, participants were asked to read and agree to informed consent and acknowledgement of their voluntary participation, including issues of confidentiality. Therefore, this is a convenience sample recruited online, and this is necessarily limited to those who have access to the Internet (Neves \& Amaro, 2012), and have the inclination to spend time online answering a Web-based questionnaire.

\section{Results}

\section{Sociodemographic Characteristics}

As can be seen from Table 1, results show that the majority of participants $(86.1 \%)$ live in a rented or owned house. Equal numbers lived alone as lived with their partners $(40.6 \%$ ); nearly $60 \%$ have no children (more men than women). The majority of participants assess their monthly income as sufficient but limited; $73 \%$ say that they are already retired from work. Gender comparisons present a somewhat mixed image of these demographic circumstances; the social vulnerabilities of men were apparent in that men were significantly more likely to live alone and without children. At the same time, the financial resources of men exceeded those of women in that men were more likely to own or rent a home and had relatively greater incomes.

\section{Social Support and Interpersonal Relations}

Most participants are "out" (89.1\%), although participants still report a range of acceptance by others; only $27.7 \%$ of participants report that "most" or "everybody" accepts them. The vast majority of participants state that they have a family of choice $(75.2 \%) ; 40.6 \%$ say that their first emergency contact is their partner. Over one third (34\%) state that they have no one to take care of them in case of need; $73.3 \%$ spend most of their time at home. Only $29.7 \%$ say 
that they never feel lonely. Men are more likely to be out and accepted and are more likely to spend their time with friends than women; at the same time, the majority of men spend time at home and are more likely to report feeling lonely than women. These results can be seen in Table 2 .

\section{Physical and Sexual Health}

Table 3 highlights the results on the questions about self-assessed physical health as well as sexual behaviors. Most participants report their health status as good or very good $(43.6 \%$ and $12.9 \%$, respectively) - more women than men. Over half of the participants report that they have active sexual lives $(55.4 \%)$. Interestingly, there were no gender differences in reports on the dynamics of sexual activity, although women were (nonsignificantly) more likely to report no sexual activity (as a consequence of either poor health or the absence of a partner). Gender differences were noted on the HIV-knowledge question with a greater proportion of men reporting not having enough information on HIV/AIDS.

\section{Social and Health Services Needs and Evaluations}

Most participants $(72.4 \%)$ report that they do not use any type of health service, probably reflecting their appraisals of good health. The most valued feature of services $(48.5 \%)$ is an awareness of LGB issues by health services; the majority of women and men $(77.2 \%)$ would feel more comfortable if services were sensitive to LGB clients. About half of all participants (though more men than women) agree with the fact that there should exist exclusive care for older LGB clients. Relatedly, the majority of participants, $71.3 \%$, have not disclosed their sexual identity to their health professionals; this was the case more for women than men. Almost $40 \%$ of participants reported knowledge of discrimination of LGB older people in formal care and an even higher number $(45.5 \%)$ has already suffered discrimination in services due to their sexual orientation. These results can be seen in Table 4 .

\section{Discussion}

An emerging body of literature has examined the unique aging needs, strengths, and challenges facing LGB older adults; this literature has been predominantly North American in focus and scope. This research has challenged the negative stereotype of older LGB people as unhappy, isolated, and celibate (Hughes, 2008; Orel, 2004; Woolf, 2000). Studies show that there is wide variety of life course trajectories and attitudes to ageing that are influenced by sexual orientation, coming out histories, marital status, and friendship networks (Heaphy, Yip, \& Thompson, 2003; Hughes \& Kentlyn, 2011; Schope, 2005). The purpose of our study was to provide descriptive and sociodemographic characteristics 
Table 2. Social Support and Interpersonal Relationships, by Gender.

Women Men Total

$(n=4 \mathrm{I}),(n=60),(N=10 \mathrm{I})$,

Social Support and Interpersonal Relationships $n(\%) \quad n(\%) \quad n(\%) \quad \chi^{2}(\mathrm{df}) \quad p$

Coming out

Yes

No

Acceptance as LGB

Not accepted

Not everybody accepts

$33(80.4) 57$ (95.0) 90 (89.I) 5.286 (I) .022*

Most everybody accepts

8 (19.6) $3(5.0) \quad$ II (10.9)

Everybody accepts

Living with whom

Alone

With partner

With family

With friends

With other people

Has children

Yes

No

4 (9.8) II (18.3) I5 (14.9) II.628 (3).002*

24 (58.5) 34 (56.7) 58 (57.4)

13 (3I.7) 7 (II.7) 20 (19.8)

$0(0.0) \quad 8(13.3) \quad 8(7.9)$

I5 (36.6) 26 (43.3)4I (40.6) 10.565 (4).032*

14 (34.I) 27 (45) 4 I (40.6)

8 (19.5) $5(8.4) \quad 13(12.9)$

$-\quad 2(3.3) \quad 2(2.0)$

$4(9.8) \quad-\quad 4(4.0)$

Providing assistance to others

Yes

No

Family of choice

Yes

No

$22(53.7) 19$ (3I.7) 4 I (40.6) 4.885 (I) .039*

$19(46.3) 4 \mathrm{I}(68.3) 60(59.4)$

II (26.8) I8 (30) 29 (28.7) . I20 (I) .729

30 (73.2) 42 (70) $72(71.3)$

$33(80.5) 43(71.7) 76(75.2) \quad 1.018$ (I) .313

8 (19.5) 17 (28.3) 25 (24.8)

First emergency contact

Partner

Child

$14(34.1) 27(45) \quad 41$ (40.6) 8.400 (7) .299

$4(9.8) \quad 6(10) \quad 10(9.9)$

Parent

I (2.4) $0(0.0) \quad 0(0.0)$

Brother/sister

7 (I7.I) 4 (6.7) II (10.9)

Friends/neighbor

6 (14.6) I3 (2I.7) I9 (I8.8)

Formal care

$4(9.8) \quad 2(3.3) \quad 6(5.9)$

Other

5 (12.2) 6 (10) II (10.9)

Nobody

$0(0.0) \quad 2(3.3) \quad 2(2)$

Has someone to take care of you in case of need

Yes

30 (73.2) $37(6 \mathrm{I} .7) 67$ (66.3) 1.443 (I) .162

No

II (26.8) 23 (38.3) 34 (33.7)

With whom do you spend most of your time

Partner

18 (43.9) 24 (40) 42 (4I.6) 15.960 (4).003*

Family members

8 (I9.5) । (I.7) 9 (8.9)

Friends

4 (9.8) 17 (28.3) $21 \quad(20.8)$

Neighbors

$0(0.0) \quad 4(6.7) \quad 4(4)$

Alone

II (26.8) I 4 (23.3) 25 (24.8) 
Table 2. Continued

\begin{tabular}{|c|c|c|c|c|c|}
\hline Social Support and Interpersonal Relationships & $\begin{array}{c}\text { Women } \\
(n=4 \mathrm{I}), \\
n(\%)\end{array}$ & $\begin{array}{c}\text { Men } \\
(n=60), \\
n(\%)\end{array}$ & $\begin{array}{c}\text { Total } \\
(N=10 \mathrm{I}), \\
n(\%)\end{array}$ & $\chi^{2}(\mathrm{df})$ & $p$ \\
\hline \multicolumn{6}{|l|}{ Where do you spend most of your time } \\
\hline At home & \multicolumn{3}{|c|}{$24(58.5) 50(83.3) 74(73.3)$} & \multirow{5}{*}{\multicolumn{2}{|c|}{$\mid 8.827(4) .00 I^{* *}$}} \\
\hline At family's & $7(17.1)$ & $0(0.0)$ & $7(6.9)$ & & \\
\hline At friends' or neighbors & $3(7.3)$ & $3(5)$ & $6(5.9)$ & & \\
\hline Nursing home & $4(9.8)$ & $0(0.0)$ & $4(4)$ & & \\
\hline Day care center & $3(7.3)$ & $7(11.7)$ & $10(9.9)$ & & \\
\hline \multicolumn{6}{|l|}{ Loneliness } \\
\hline Very often & \multicolumn{3}{|c|}{5 (12.2) $22(36.8) 27(26.7)$} & \multirow{3}{*}{\multicolumn{2}{|c|}{$10.45 \mid(2) .005^{*}$}} \\
\hline Sometimes & $25(6 I)$ & $19(31.6)$ & $44(43.6)$ & & \\
\hline Never & II (26.8) & $19(31.6)$ & $30(29.7)$ & & \\
\hline
\end{tabular}

$*_{p}<.05 .{ }^{* *} p<.001$.

Table 3. Physical and Sexual Health, by Gender.

\begin{tabular}{|c|c|c|c|c|c|}
\hline Physical and Sexual Health & $\begin{array}{c}\text { Women } \\
(n=4 I) \\
n(\%)\end{array}$ & $\begin{array}{c}\text { Men } \\
(n=60), \\
n(\%)\end{array}$ & $\begin{array}{c}\text { Total } \\
(n=10 \mathrm{I}) \\
n(\%)\end{array}$ & $\chi^{2}(\mathrm{df})$ & $p$ \\
\hline \multicolumn{6}{|l|}{ Self-assessment of health status } \\
\hline Very good & $3(7.3)$ & $10(16.7)$ & $13(12.9)$ & $12.492(3)$ & $.006 *$ \\
\hline Good & $26(63.4)$ & $18(30)$ & $44(43.6)$ & & \\
\hline Fair & $12(29.3)$ & $28(46.7)$ & $40(39.6)$ & & \\
\hline Poor & $0(0)$ & $4(6.6)$ & $4(4.0)$ & & \\
\hline \multicolumn{6}{|l|}{ Sexual life } \\
\hline Active & $25(6 I)$ & $3 \mid(5 \mid .7)$ & $56(55.4)$ & $.854(\mathrm{I})$ & .236 \\
\hline Inactive & $16(39)$ & $29(48.3)$ & $45(44.6)$ & & \\
\hline \multicolumn{6}{|l|}{ Dynamics of sexual activity } \\
\hline Sex with only one partner & I7 (4I.5) & $18(30)$ & $35(34.7)$ & 7.165 & .127 \\
\hline Open relationship & $3(7.3)$ & $15(25)$ & I8 (I7.8) & & \\
\hline Casual sex & $2(4.9)$ & $6(10)$ & $8(7.9)$ & & \\
\hline No activity due to lack of partner & $16(39)$ & $19(31.7)$ & $35(34.7)$ & & \\
\hline No activity due to health problems & $3(7.3)$ & $2(3.3)$ & $5(5.0)$ & & \\
\hline \multicolumn{6}{|l|}{ HIV/STD information } \\
\hline Yes & $36(87.8)$ & 43 (7I.7) & $79(78.2)$ & $3.720(1)$ & $.044^{*}$ \\
\hline No & $5(12.2)$ & $17(28.3)$ & $22(21.8)$ & & \\
\hline
\end{tabular}

$* p<.05$. 
Table 4. Social and Health Service Needs and Evaluation, by Gender.

\begin{tabular}{|c|c|c|c|c|c|}
\hline Social and Health Service Needs & $\begin{array}{c}\text { Women } \\
(n=4 I) \\
n(\%)\end{array}$ & $\begin{array}{c}\text { Men } \\
(n=60), \\
n(\%)\end{array}$ & $\begin{array}{c}\text { Total } \\
(N=10 \mathrm{I}) \\
n(\%)\end{array}$ & $\chi^{2}(\mathrm{df})$ & $p$ \\
\hline \multicolumn{6}{|l|}{ Type of health services used } \\
\hline Home support & $2(4.9)$ & $3(5)$ & $5(5.1)$ & $|5.0| \mid(4)$ & $.005^{*}$ \\
\hline Nursing home & $5(12.2)$ & $0(0)$ & $5(5.1)$ & & \\
\hline Day care center & $3(7.3)$ & $0(0)$ & $3(3.1)$ & & \\
\hline Support groups & $7(17)$ & 7 (II.7) & $14(14.3)$ & & \\
\hline No services & $24(58.6)$ & $50(83.3)$ & $74(73.4)$ & & \\
\hline \multicolumn{6}{|c|}{ Valued features of services for older clients } \\
\hline Location & $3(7.3)$ & $6(10)$ & $9(8.9)$ & $7.254(3)$ & .064 \\
\hline Comfort & $13(31.7)$ & $11(18.3)$ & $24(23.8)$ & & \\
\hline LGB awareness & $22(53.7)$ & $27(45)$ & $49(48.5)$ & & \\
\hline LGB specific care & $3(7.3)$ & $16(26.7)$ & $19(18.8)$ & & \\
\hline \multicolumn{6}{|c|}{ Would feel more comfortable if services were sensitive to LGB clients } \\
\hline Yes & $34(83)$ & $44(73.3)$ & $78(77.2)$ & $1.275(1)$ & .188 \\
\hline No & $7(17)$ & $16(36.7)$ & $23(22.8)$ & & \\
\hline \multicolumn{6}{|c|}{$\begin{array}{l}\text { Knowledge of discrimination of LGB older people in formal care } \\
\text { (knows of people who were discriminated against) }\end{array}$} \\
\hline Yes & $20(48.8)$ & $20(33.3)$ & $40(39.6)$ & $2.430(1)$ & .088 \\
\hline No & $21(51.2)$ & $40(66.6)$ & $61(60.4)$ & & \\
\hline \multicolumn{6}{|c|}{ Has suffered discrimination in services due to sexual orientation } \\
\hline Yes & $16(39)$ & $30(50)$ & $46(45.5)$ & $1.183(1)$ & .188 \\
\hline No & $25(61)$ & $30(29,7)$ & $55(54.5)$ & & \\
\hline \multicolumn{6}{|c|}{ Coming out to health professional } \\
\hline Yes & $6(14.6)$ & $23(38.3)$ & $29(28.7)$ & $6.683(1)$ & $.008^{*}$ \\
\hline No & $35(85.4)$ & $37(61.7)$ & $72(71.3)$ & & \\
\hline \multicolumn{6}{|c|}{ Exclusive care for older LGB clients? } \\
\hline Yes & $18(43.9)$ & $38(63.3)$ & $56(55.4)$ & $3.723(I)$ & $.042^{*}$ \\
\hline No & $23(56.1)$ & $22(36.7)$ & $45(44.6)$ & & \\
\hline
\end{tabular}

Note. $\mathrm{LGB}=$ Lesbian, Gay, and Bisexual.

$* p<.05$.

about the LGB population, 65 years of age and older, in Lisbon to both share results from a region of the world not frequently represented in the LGBT aging literature and to further foster a better understanding of the needs and resources of this historically marginalized and invisible population.

\section{Socioeconomic Status}

Higher levels of education (consistent with North American research, e.g., MetLife Mature Market Institute, 2010) and average monthly incomes (500 euro; PORDATA, 2018) characterize our sample. Women, however, 
reported lower incomes than men, consistent with North American research (Bertrand, Kamenica, \& Pan, 2015). That over $40 \%$ believed their incomes were "sufficient but limiting," further dispels the myth of the "wealthy gay" demographic, echoing other research on income disparities in this population (Black, Makar, Sanders, \& Taylor, 2003; Martell, 2010; Prokos \& Keene, 2010).

The vast majority of participants live in owned or rented houses, similar to trends noted in North American research (and perhaps expected among an urban population). Equal proportions of the sample (40\%) live alone or live with a partner which did not differ by gender. This interestingly diverges from the findings of several North American studies which report that men significantly more likely live alone than do women and hence are likely at greatest risk for isolation (Fredriksen-Goldsen, Kim, Emlet, Muraco, \& Erosheva, 2011; Grossman, D’Augelli, \& Hershberger, 2000; Shippy, Cantor, \& Brennan, 2004), modestly supported in our study (see later). Consistent with previous research in Portugal, and tradition in Portuguese society, women were more likely to live with a family member than were men, perhaps due to more financial vulnerability (Moura, Spindler, \& Taylor, 2015).

\section{Social Support and Interpersonal Relations}

We found that the majority of participants (almost 90\%) reported they were "out" as gay, lesbian, or bisexual adults. At the same time, more than $58 \%$ report that not everyone accepted their sexual orientation in addition to the almost $15 \%$ who stated that they were not accepted. We interpret this as evidence of the conservative nature of Portugal society and higher than typically reported in North American research (e.g., Gardner, de Vries, \& Mockus, 2014).

Just over $40 \%$ of the sample lived alone, somewhat higher for men than for women, consistent with much North American research (e.g., Wallace et al., 2011), even as these percentages are somewhat lower. The majority of both women and men report spending most of their time at home; apart from spending time with partners, the most endorsed category describing with whom time was spent was alone (about $25 \%$ of the sample). Relatedly, over a quarter of the sample reported that they were lonely "very often." As has also been found in North American studies (e.g., Kuyper \& Fokkema, 2010), men reported greater loneliness than women.

Still, three quarters of the sample said they had a "chosen family" - slightly higher than what has been found in North American research (e.g., MetLife Mature Market Institute, 2010). Partners and friends were frequently identified as emergency contacts (again, similar to findings from North America; e.g., MetLife Mature Market Institute, 2010), especially by men. The responses by women were more widely distributed. Even though about $40 \%$ of the sample responded that they had children (with a greater proportion of women than men), less than $10 \%$ of participants identified children as their first emergency 
contact. This too is comparable to U.S. research (Fredriksen-Goldsen et al., 2013). Although the biological family is present, many family members are not connected with these LGB older adults and cannot be classified as functional members of the social care system.

Importantly, over one third of participants report that they do not have someone to take care of them in a time of need (even as over $28 \%$ of participants provide care for someone). Such numbers coincide with the proportions of participants who reported feeling lonely. These numbers are sadly familiar to those conducting research into the lives of older LGB persons across nations and represent a true call to action in support of LGB older adults, particularly given their higher physical health-care needs (Fredriksen-Goldsen et al., 2012).

\section{Physical and Sexual Health}

Interestingly, the rates of good and fair health of the LGB persons in this sample are somewhat higher than comparable North American research (e.g., Fredriksen-Goldsen et al., 2012). Greater than half of the sample is sexually active (consistent with the findings of Lindau et al., 2007 with a large national probability sample of primarily heterosexual older adults), with no significant differences between men and women. Lindau et al. (2007) also reported, however, that women (at all ages) were significantly less likely to report sexual activity than were men. Our findings of no significant difference offer an interesting contrast; it is difficult to determine if the differences are sexual orientation or nationality, or both to some degree, but further research is certainly suggested.

Almost one quarter of the sample reports not having information about HIV/ STD, probably, in this case, associated with a lower socioeconomic level (Sankar, Nevedal, Neufeld, Berry, \& Luborsky, 2011). Evocatively, gender differences were noted with a higher proportion of men reporting that they lacked knowledge. Given the frequency with which HIV/AIDS messages are targeted to men, these data represent a significant mismatch and merit further attention.

\section{Social and Health Service Needs and Evaluation}

Research on service needs among older adults is only beginning to addresses the special circumstances of LGB individuals, such as their reliance on friendcentered social networks or the experience of discrimination from service providers (Brennan-Ing et al., 2014). Importantly, almost half of the participants reported having experienced sexual orientation discrimination in health or social services and about 40\% have personal knowledge of LGB persons having experienced discrimination in formal care settings, higher than the limited comparable research-17\% in the study of Fredriksen-Goldsen et al. (2011). 
The high rates of experienced discrimination, and knowledge of the same, almost certainly underlie the reticence of the LGB older adults in this sample to come out to their health professional. Almost three quarters of the sample noted that they have not come out, though percentages were higher for women than for men. Gardner et al. (2014) report similar such gender differences in their USbased research and question the gendered experience and perceptions of safety, as exhibited by older LGBT persons.

Even as the majority of participants do not presently use medical or social services (moreso for men than it was for women), LGBT awareness was one of the most valued features of services for older clients. Over three quarters of participants noted that they would feel comfortable if services were sensitive to LGBT clients. Along comparable lines, Gardner et al. (2014) indicated that the majority of their participants (women more than men) would feel more comfortable using services that identified as LGBT-inclusive. Such services are rare, however. For example, Knochel, Quam, and Croghan (2011) found that only $2 \%$ of aging service providers offered gay- and lesbian-specific services. Another study found that only a little more than $10 \%$ of substance abuse treatment centers had services tailored for the LGB population (Hughes \& Kentlyn, 2011). Further research and tailored action are clearly needed.

The answer is not necessarily exclusive LGBT medical and social services; our participants were mixed in their endorsement of exclusive LGBT care settings; just over half (55\%) endorsed such care contexts where as $46 \%$ opposed. Silos of care only fragment an already disrupted system; more sensitive and inclusive care serves everyone better.

\section{Conclusion}

Across North American and Portuguese cultures, LGB older adults may be described by similar socioeconomic characteristics (e.g., higher education, average income), reports of loneliness, distance from families, and the absence of someone on whom to rely for care when needed. Comparable rates of preference for use of services that identified as LGBT-inclusive were identified. Cultural differences were noted in several contexts: Higher percentages of the Portuguese sample reported having experienced sexual orientation discrimination in health or social services; at the same time, our sample reported higher rates of better health than has been seen in NA studies - and higher rates of reported sexual activity - with no gender differences. Evocatively, gender differences were noted that do not often appear in North American research. For example, the proportions of women living alone and living with family are higher than might be anticipated by existing research. Together, these findings help set the stage for subsequent efforts.

Although this study broadly characterizes the LGB older population of Lisbon, further work is required to identify aging issues, concerns, and needs 
relevant to the diversity of LGB communities, many of whom experience additional barriers to services. The key findings point to opportunities for interventions (e.g., social outreach) and organizational changes (e.g., ensuring LGBT-inclusiveness) that will ensure LGB and $\mathrm{T}$ individuals have quality support services and care as they age.

\section{Limitations}

This is an important early step in the description and understanding of the lives of LGB older adults in Portugal. Nonetheless, this study has limitations; paramount among these is the absence of transgender persons in analyses. Similarly, the bisexual sample of older adults was insufficient to allow reliable analyses further divided by gender. The sample as a whole was urban and sufficiently comfortable with technology to respond to an online survey. Even as this is more common in the United States, estimates are that smaller percentages of Portuguese older adults are comfortable with this technology and, as a consequence, the sample thereby derived may be unlike others recruited through more traditional methods and using more traditional methodologies.

\section{Future Directions and National Implications}

The findings of this study can be used to engage the community in a dialogue on how to effectively serve LGB older adults. Models for such effective outreach exist; the National Health, Aging, Sexuality/Gender study: Aging with Pride (Fredriksen-Goldsen et al., 2011) emerges as a prominent example. From our study, we would comparably recommend the development of services to address the mostly unmet and critical social and health (including sexual) needs of older LGB adults in settings that are LGB-affirmative and inclusive. Developing strategies to combat the discrimination reported and anticipated in health and social service settings (and beyond) must be a critical component of any such strategy. Similarly, programs to help identify and support caregivers would be worthy additions. All of these recommendations are bracketed by the need to consider and address the particular and unique needs of the groups that comprise the LGBT umbrella. Advocacy on behalf of older LGBT adults, across cultures and settings, is an important effort in this regard including the collection of data on the aging and health needs of older LGB adults.

To date, little attention has been given to the needs of LGB older people in Lisbon and in Portugal; thus, descriptive studies like ours are necessary not only to map areas of intervention but also to inform policy makers about the measures that will improve the everyday life of marginalized groups. This could involve creating meaningful partnerships with aging agencies, both governmental and nongovernmental, to consider older LGB people a vulnerable subgroup of the older population that have unique experiences and needs. The education 
and training of practitioners in these areas in Portugal often lacks information on LGB older adults, so our results also have implications to the field of geriatric care whose goal is the promotion of the health and well-being of all individuals as they age. Finally, continued research is suggested; in addition to their inclusion in aging research, measures related to sexual orientation must be incorporated in order to allow accurate information to emerge.

\section{Acknowledgments}

We would like to thank Opus Gay Association in Lisbon, Portugal and its members, for allowing us to participate in the Project "Growing Old Out of the Closet" focusing on LGBT Older Adults.

\section{Declaration of Conflicting Interests}

The authors declared no potential conflicts of interest with respect to the research, authorship, and/or publication of this article.

\section{Funding}

The authors received no financial support for the research, authorship, and/or publication of this article.

\section{ORCID iD}

Henrique Pereira (D) http://orcid.org/0000-0001-9448-682X

Brian de Vries (D) http://orcid.org/0000-0003-4360-1343

\section{References}

Bertrand, M., Kamenica, E., \& Pan, J. (2015). Gender Identity and Relative Income within Households. The Quarterly Journal of Economics, 130(2), 571-614.

Black, D., Makar, H., Sanders, S., \& Taylor, L. (2003). The earnings effects of sexual orientation. Industrial and Labor Relations Review, 56, 3.

Brennan-Ing, M., Seidel, L., Larson, B., \& Karpiak, S. E. (2014). Social care networks and older LGB adults: Challenges for the future. Journal of Homosexuality, 61, 21-52.

de Vries, B., \& Hoctel, P. (2007). The family friends of older gay men and lesbians. In N. Teunis \& G. Herdt (Eds.), Sexual inequalities and social justice (pp. 213-232). Berkeley, CA: University of California Press.

Fredriksen-Goldsen, K. I., Emlet, C. A., Kim, H., Muraco, A., Erosheva, E. A., Goldsen, J., \& Hoy-Ellis, C. P. (2012). The physical and mental health of lesbian, gay male, and bisexual (LGB) older adults: The role of key health indicators and protective factors. The Gerontologist, 53, 664-675.

Fredriksen-Goldsen, K. I., Kim, H. J., Emlet, C. A., Muraco, A., \& Erosheva, E. (2011). The aging and health report: Disparities and resilience among lesbian, gay, bisexual, and transgender older adults. Seattle, WA: Institutional for Multigenerational Health.

Fredriksen-Goldsen, K. I., Kim, H. J., Hoy-Ellis, C. P., Goldsen, J., Jensen, D., Adelman, M., Costa, M., \& de Vries, B. (2013). Addressing the needs of LGB older 
adults in San Francisco: Recommendations for the future (Report prepared for the LGB Aging Policy Task Force). Seattle, WA. Institute for Multigenerational Health. Gardner, A., de Vries, B., \& Mockus, D. (2014). Aging out in the desert: Disclosure, acceptance, and service use among midlife and older lesbian and gay men in Riverside County. Journal of Homosexuality, 61(1), 129-144.

Grossman, A. H., D’Augelli, A. R., \& Hershberger, S. L. (2000). Social support networks of lesbian, gay, and bisexual adults 60 years of age or older. Journal of Gerontology: Psychological Sciences, 55B, 171-179.

Heaphy, B., Yip, A., \& Thompson, D. (2003). Lesbian, gay and bisexual lives over 50: A report on the project 'The social and policy implications of non-heterosexual ageing'. Nottingham, England: York House Publications.

Hughes, M. (2007). Older lesbians and gays accessing health and aged-care services. Australian Social Work, 60, 197-209.

Hughes, M. (2008). Imagined futures and communities: Older lesbian and gay people's narratives on health and aged care. Journal of Gay and Lesbian Social Services, 20, 167-186.

Hughes, M., \& Kentlyn, S. (2011). Older LGBT people's care networks and communities of practice: A brief note. International Social Work, 54, 436-444.

Jackson, N. C., Johnson, M. J., \& Roberts, R. (2008). The potential impact of discrimination fears of older gays, lesbians, bisexuals and transgender individuals living in small-tomoderate-sized cities on long-term health care. Journal of Homosexuality, 54, 325-339.

Knochel, K. A., Quam, J. K., \& Croghan, C. F. (2011). Are old lesbian and gay people well served? Understanding the perceptions, preparation, and experiences of aging services providers. Journal of Applied Gerontology, 30, 370-389.

Kuyper, L., \& Fokkema, T. (2010). Loneliness among older lesbian, gay, and bisexual adults: The role of minority stress. Archives of Sexual Behavior, 39(5), 1171-1180.

Lindau, S. T, Schumm, L. P., Laumann, E. O., Levinson, W., O’Muircheartaigh, C. A., \& Waite, L. J. (2007). A study of sexuality and health among older adults in the United States. New England Journal of Medicine, 357, 764-774.

Lopes, D., Oliveira, J. M., Nogueira, C., \& Grave, R. (2017). The social determinants of polymorphus prejudice against lesbian and gay individuals: The case of Portugal. Sexuality Research and Social Policy, 14(1), 56-70.

Marques, F. D., \& Sousa, L. (2016). Portuguese older gay men: Pathways to family integrity. Paidéia, 26(64), 149-159. doi:10.1590/1982-43272664201602

Martell, M. E. (2010). Why do homosexual men earn less than heterosexual men, despite an invisible minority trait? Retrieved from http://www.american.edu/cas/economics/pdf/ upload/Paper-Martell.pdf

MetLife Mature Market Institute. (2010). Still out, still aging. Westport, CT: MetLife Mature Market Institute.

Moura, T., Spindler, E., \& Taylor, A. (2015). Portugal's masculinities crisis: Gender equality in the era of flagging economies. Ex aquo, 32, 87-100.

Neves, B. B., \& Amaro, F. (2012). Too old for technology? How the elderly of Lisbon use and perceive ICT. The Journal of Community Informatics, 8,1.

Oliveira, J. M., Costa, C., \& Nogueira, C. (2013). The workings of homonormativity: Lesbian, gay, bisexual, and queer discourses on discrimination and public displays of affections in Portugal. Journal of Homosexuality, 60, 1475-1493. 
Orel, N. (2004). Gay, lesbian, bisexual elders: Expressed needs and concerns across focus groups. Journal of Gerontological Social Work, 43(2-3), 57-77.

PORDATA. (2018). Pensão média anual da Segurança Social: Total, de sobrevivência, de invalidez e de velhice [Average annual Social Security pension: Total, survivor, invalidity and old age pension]. Retrieved from https://www.pordata.pt/Portugal/Pensã $\mathrm{o}+$ média + anual + da + Segurança + Social + total ++ de + sobrevivência ++ de + invalidez $+\mathrm{e}+\mathrm{de}+$ velhice-706-5158

Pereira, H., \& Monteiro, S. (2016). The role of political and legislative changes in the everyday lives of LGB individuals: The case of Portugal. Sexuality Research and Social Policy, 14, 300-309. doi:10.1007/s13178-016-0261-x

Pereira, H, Serrano, J. P., de Vries, B., Esgalhado, G., Afonso, R. M., \& Monteiro, S. (2017). Aging perceptions in older gay and bisexual men in Portugal: A qualitative study. The International Journal of Aging and Human Development, 87, 5-32. doi:10.1177/0091415017720889

Prokos, A. H., \& Keene, J. R. (2010). Poverty among cohabiting gay and lesbian, and married and cohabiting heterosexual families. Journal of Family Issues, 31, 934-959.

Sharek, D. B., McCann, E., Sheerin, F., Glacken, M., \& Higgins, A. (2015). Older LGB people's experiences and concerns with healthcare professionals and services in Ireland. International Journal of Older People Nursing, 10, 230-240.

Shippy, R. A., Cantor, M. H., \& Brennan, M. (2004). Social networks of aging gay men. The Journal of Men's Studies, 13(1), 107-120.

Schope, R. D. (2005). Who's afraid of growing old? Gay and lesbian perceptions of aging. Journal of Gerontological Social Work, 45(4), 23-38.

Wallace, S. P., Cochran, S. D., Durazo, E. M., \& Ford, C. L. (2011). The health of aging lesbian, gay and bisexual adults in California. Los Angeles, CA: UCLA Center.

Woolf, R. S. (2000). Elder abuse: An introduction. Generations, 20(4), 301-305.

Sankar, A., Nevedal, A., Neufeld, S., Berry, R., \& Luborsky. (2011). What do we know about older adults and HIV? A review of social and behavioral literature. AIDS Care, 23(10), 1187-1207.

Instituto Nacional de Estatística. (2012). Censos 2011 Resultados Definitivos-Portugal. Lisboa, Portugal: INE, I.P.

\section{Author Biographies}

Henrique Pereira holds a PhD in clinical psychology. He is an assistant professor at the University of Beira Interior, Portugal. His research focuses on LGBT Psychology.

Brian de Vries is the professor emeritus of gerontology at San Francisco State University, USA. His extensive research focuses on LGBT aging and end of life.

António Serzedelo is an activist, journalist, actor, and an academic in Portugal. He is the founder and chairperson of Opus Gay, an LGBT organization based in Lisbon, Portugal. 
Juan Pedro Serrano holds a PhD in Psychology from the University of CastillaLa Mancha (Spain). He is an associate professort the same University (Department of Psychology of the School of Medicine). His research focuses on aging.

Rosa Marina Afonso holds a PhD in Psychology. She is an assistant professor at the University of Beira Interior, Portugal. Her research focuses on aging.

Graça Esgalhado holds a PhD in psychology. She is an assistant professor at the University of Beira Interior, Portugal. Her research focuses on human development.

Samuel Monteiro holds a PhD in psychology. He is an assistant professor at the University of Beira Interior, Portugal. His research focuses on occupational health. 